\title{
DESIGN OPTIMIZATION \& EXPERIMENTS ON FLYWHEEL USING THRESHER MACHINE
}

\author{
Sagar M. Samshette ${ }^{1}$, Mahesh C. Swami ${ }^{2}$ \\ ${ }^{1}$ Student of M.E. Mechanical Machine Design, M.S.Bidve Engineering College Latur, Maharashtra, India \\ ${ }^{2}$ Prof, Department of Mechanical Engineering, M.S.Bidve Engineering College Latur, Maharashtra, India
}

\begin{abstract}
Flywheel used in multicrop thresher is a solid disk flywheel. Solid flywheels are capable of storing less energy. It is made up of cast iron. The material induced in solid disk flywheel is large so weight of the flywheel increased as a result cost of the flywheel also increases and size of the motor used to rotate the solid disk flywheel is also increased so overall cost of the thresher is also increased. High weight of flywheel also increases the operational loads coming on to the shaft and bearing. This experimental project work carried out to improve the efficiency of thresher is focused on to the flywheel. Initially we measure RPM of solid disk flywheel then with the help of ANSYS we optimized mass of solid disk flywheel then we prepare optimized six spoke flywheel and install same flywheel on shaft of thresher machine, measure RPM of optimized six spoke flywheel finally we calculate various functional value from the comparative result study we are able to success $12 \%$ material cost with less operational loads on to the shaft and bearing and high storing capacity of kinetic energy.
\end{abstract}

Key Words: Flywheel, Thresher Machine, Mass Optimization, ANSYS, Kinetic Energy.

\section{INTRODUCTION}

Thresher machine much popular in Indian agriculture sector for threshing grains. Thresher machine are power driven constructed for separate the comb from grain. Thresher machine take power from electric motors or diesel engines. These machine are easily available in number of models by different output capacity. These machines used to separate the cob from grains. Now in India most of the farmer's used thresher's machine for threshing grain like soybean, maize, wheat, jawar, etc. In previous year farmer resort manual means of threshing, which results into less efficiency, more wastage and much cost spend on labor. Thresher machine constructed for separate cob from the grain. It was constructed from locally available and its cost is very low, affordable, easy transportable

\section{THRESHING MECHANISM}

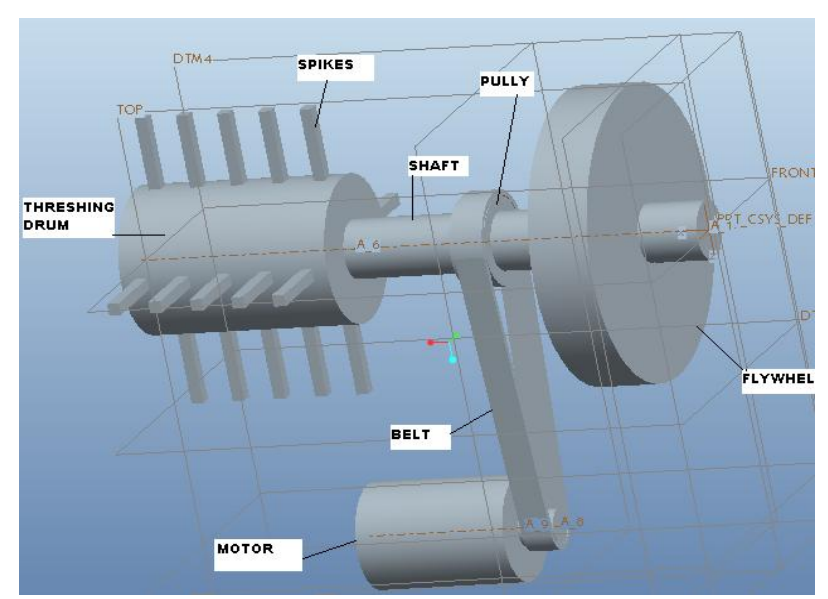

Fig -1: Mechanism of Single Flywheel Multicrop Thresher
The Threshing operation is performed by threshing drum provided or mounted on the shaft. The shaft is rotated by the electric motor fixed at one end. The size of the motor is 5 $\mathrm{HP} / 3.7 \mathrm{KW}$. The shaft is provided with threshing drum at one end and the solid disk flywheel at other end. The threshing drum provided with number of spikes which are used to thresh the crops. The spikes used to separate the cob from the grains. The threshing drum and overall assembly is covered by threshing chamber. Maximum rpm of the shaft is 800. The material which is to be threshed is provided from the hopper. The crops threshed by multi crop thresher are wheat, maize, jawar, soyabean etc. The material remain after threshing operation such as shell and grains drops on the net and the blower is provided to throw out the removed shells. The grains drop into the collecting chamber or collector through the net. The shaft rotated by electric motor with the help of belt and pulley system. The $\mathrm{V}$ belt is used for transmission of power.

\section{SINGLE FLYWHEEL MULTICROP THRESHER MACHINE SPECIFICATION}

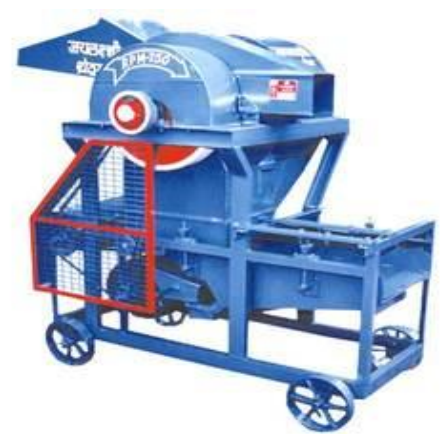

Fig -2: Single Flywheel Multicrop Thresher 
Type: Spike Tooth.

Feeding System: Hopper

Power Required: 5 H.P.

Flywheel: Single

RPM: 750

Drive: V-Belt

Weight: $360 \mathrm{Kg}$ (Approximately)

\section{EXPERIMENT ON MULTICROP THRESHER} MACHINE WITH SOLID DISK FLYWHEEL.

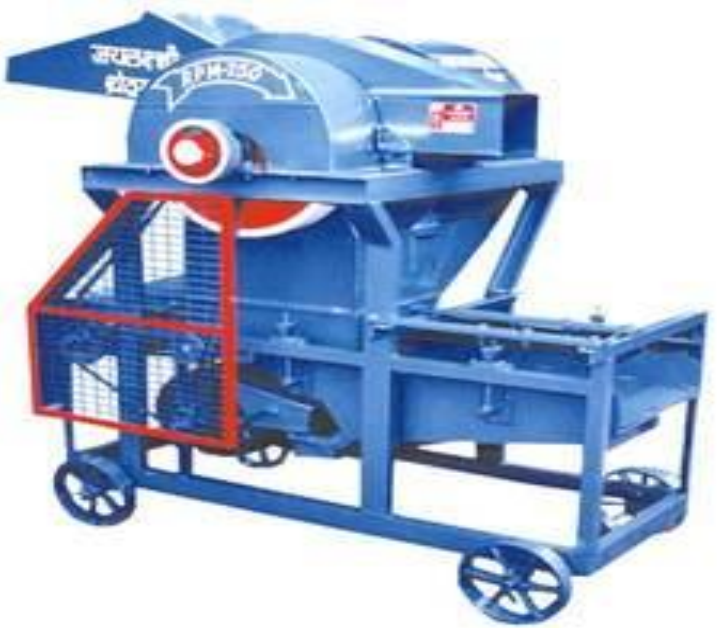

Fig -3: Single Flywheel Multicrop Thresher

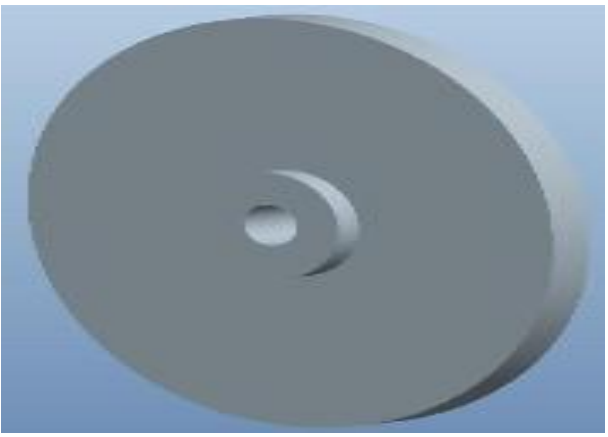

Fig -4: Solid Flywheel

In single flywheel multicrop thresher solid disk flywheel is used to store the energy. It stores the energy when supply is greater than the requirement and releases energy when requirement is greater than supply. Solid disk flywheel used in the single flywheel thresher is made up of cast iron material. Solid disk flywheel is provided with hub and disk. Solid disk flywheels are less capable of storing energy. In experiment calculation of solid disk flywheel various parameters are used as inputs such as dimensions of solid disk flywheel and resulting functional values of solid disk flywheel are calculated.

Various parameters of solid disk flywheel are given as follows.

Density $(\rho)=7510 \mathrm{~kg} / \mathrm{m}^{3}[1]$

Poisons ratio $(v)=0.23[1]$

Material ---- gray cast iron

From experimentation we got following result
$\mathrm{N}=738$ (Measured with help of tachometer)

Mass of solid disk flywheel $=60 \mathrm{~kg}$

Moment of Inertia of solid disk flywheel $=1.7594 \mathrm{~kg}-\mathrm{m}^{2}[2]$

Outer diameter of disk $\left(D_{\text {o disk }}\right)=500 \mathrm{~mm}$

\section{MASS OPTIMIZATION BY ANSYS}

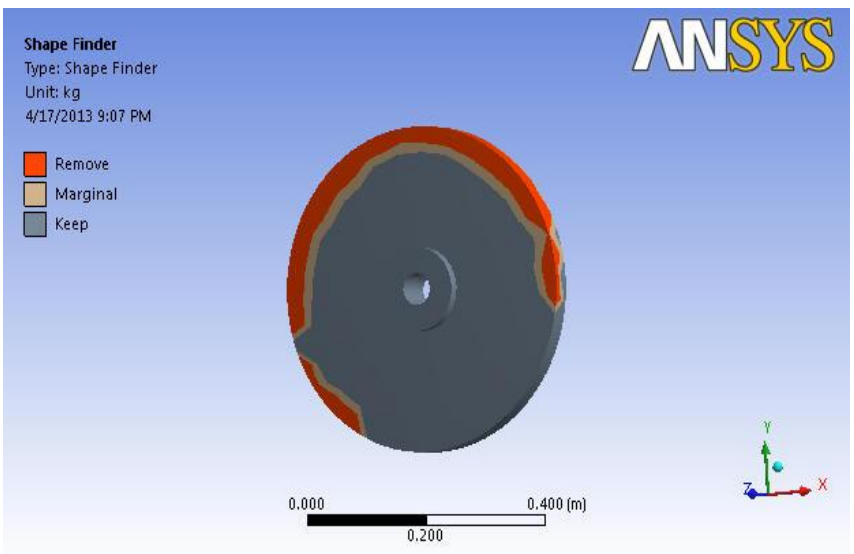

Fig -5: Shape Optimization By ANSYS

Table -1: Shape Optimization By ANSYS

\begin{tabular}{|r|c|}
\hline Object Name & Shape Finder \\
\hline State & Solved \\
\hline Scope & \\
\hline Geometry & All Bodies \\
\hline Definition \\
\hline Target Reduction & $12 . \%$ \\
\hline Results & \\
\hline Original Mass & $60.000 \mathrm{~kg}$ \\
\hline Optimized Mass & $52.368 \mathrm{~kg}$ \\
\hline
\end{tabular}

Shape optimization of solid disk flywheel is done by Ansys 11.0. The shape finder is used for the shape optimization of flywheel. The target reduction for the solid disk flywheel is $12 \%$. The material of the solid disk flywheel of thresher is gray cast iron. It allows finding the optimized mass and the marginal mass. The outer portion of flywheel at periphery represented by red colour can be removed to get the optimized mass. It also shows the marginal mass and the mass which is to be kept to get the optimized mass for the $12 \%$ target reduction. The original mass of solid disk flywheel of thresher which is to be optimized is $60 \mathrm{~kg}$ and optimized mass for the $12 \%$ target reduction found to be $52.368 \mathrm{~kg}$. The marginal mass for solid disk flywheel is allowed to be $0.020304 \mathrm{~kg}$. Model of the object whose shape optimization is to be done is created with the help of PRO-E modeling software and the model is introduced into the ANSYS for the shape optimization. 


\section{EXPERIMENT ON MULTICROP THRESHER} MACHINE WITH OPTIMIZED SIX SPOKE

\section{FLYWHEEL.}

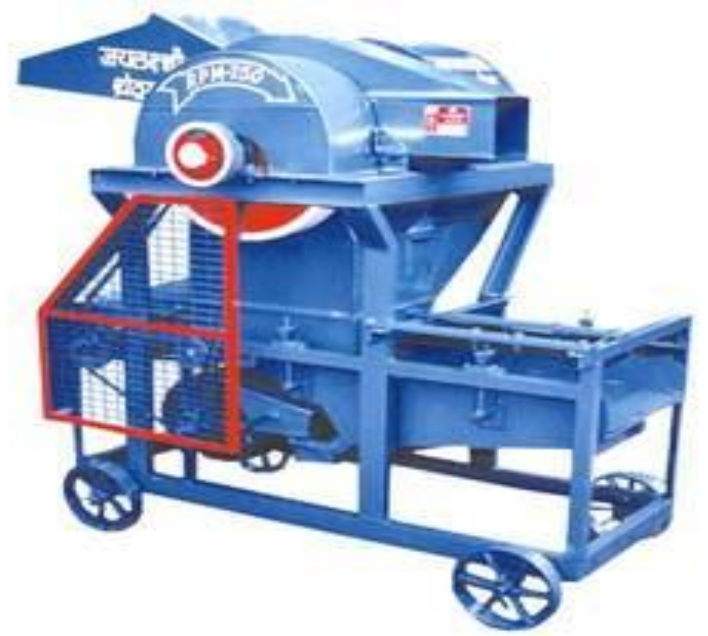

Fig -5: Single Flywheel Multicrop Threshe

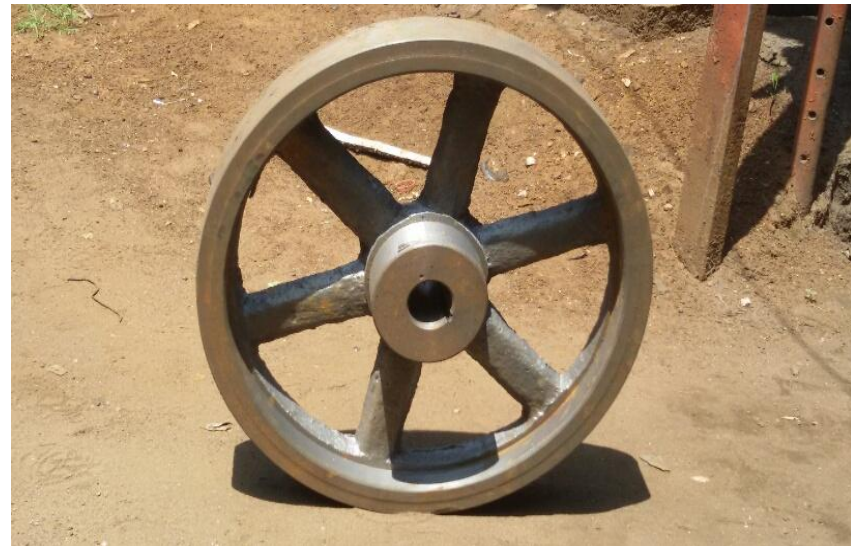

Fig -6: Optimized Six Spoke Flywheel

It is a flywheel provided with higher mass at its periphery called as rim and rim is connected to the hub with the help of spokes called spoke type flywheel.Spoke type flywheel are capable of storing more energy with greater moment of inertia than any other type of flywheel. By providing various parameters of flywheel respective functional values for the optimal spoke type flywheel are calculated.

Various parameters of spoke type flywheel are given as follows

Density $(\rho)=7510 \mathrm{~kg} / \mathrm{m}^{3}[3]$

Poisons ratio $(v)=0.23[3]$

Material ---- gray cast iron

From experimentation we got following result

$\mathrm{N}=738$ (Measured with help of tachometer)

Mass of solid disk flywheel $=52 \mathrm{~kg}$

Moment of Inertia of solid disk flywheel $=2.4016 \mathrm{~kg}$ $\mathrm{m}^{2}[1]$

\section{CALCULATION \\ FUNCTIONAL VALUES}

FOR

VARIOUS

\section{are

$$
\begin{aligned}
& =2 \times \pi \times 738 / 60 \\
\omega & =77.28 \mathrm{rad} / \mathrm{sec} \\
\text { Surface speed }\left(\mathrm{v}_{\mathrm{s}}\right) & =\pi \times \mathrm{D} \times \mathrm{N} / 60[4] \\
= & \pi \times 0.500 \times 738 / 60 \\
\mathrm{v}_{\mathrm{s}} & =19.32 \mathrm{~m} / \mathrm{s}
\end{aligned}
$$$$
\text { Angular velocity }(\omega)=2 \times \pi \times \mathrm{N} / 60[4]
$$

7.1 Various Functional values of solid disk flywheel

Energy stored in flywheel $\left(\mathrm{E}_{\mathrm{k}}\right)=1 / 2 \times \mathrm{I}_{\text {total }} \times \omega^{2}[4]$

$$
\begin{aligned}
& =1 / 2 \times 1.7594 \times 77.28^{2} \\
\mathrm{E}_{\mathrm{k}} & =5.253 \mathrm{KJ}
\end{aligned}
$$

Specific energy $\left(E_{k}, m\right)=E_{k} / M_{\text {total }}[4]$

$$
=5.253 / 60
$$$$
\left(\mathrm{E}_{\mathrm{k}}, \mathrm{m}\right)=0.087 \mathrm{~kJ} / \mathrm{kg}
$$

Energy Density $\left(E_{k}, v\right)=\left(E_{k} / M_{\text {total }}\right) \times \rho[4]$

$$
=0.087 \times 7510
$$

$$
\left(\mathrm{E}_{\mathrm{k}}, \mathrm{v}\right)=653.37 \mathrm{KJ} / \mathrm{m}^{3}
$$

\subsection{Various Functional values of Optimized Six}

\section{Spoke flywheel are}

$$
\begin{aligned}
& \text { Angular velocity }(\omega)=2 \times \pi \times \mathrm{N} / 60[4] \\
& =2 \times \pi \times 738 / 60 \\
& \omega=77.28 \mathrm{rad} / \mathrm{sec} \\
& \text { Surface speed }\left(\mathrm{v}_{\mathrm{s}}\right)=\pi \times \mathrm{D} \times \mathrm{N} / 60[4] \\
& =\pi \times 0.520 \times 738 / 60 \\
& \mathrm{v}_{\mathrm{s}}=20.09 \mathrm{~m} / \mathrm{s} \\
& \mathrm{E}_{\mathrm{k}}=7.171 \mathrm{KJ} \\
& =7.171 / 52 \\
& \left(\mathrm{E}_{\mathrm{k}}, \mathrm{m}\right)=0.1379 \mathrm{KJ} / \mathrm{kg} \\
& \text { Energy Density }\left(E_{k}, v\right)=\left(E_{k} / M_{\text {total }}\right) \times \rho[4] \\
& =0.1379 \times 7510 \\
& \left(E_{k}, v\right)=1035.62 \mathrm{KJ} / \mathrm{m}^{3}
\end{aligned}
$$

\section{RESULT}

The results obtained from experiment for the existing solid disk flywheel and optimized six spoke flywheel on the basis of their functional values. From comparison it is found that energy stored into the six spoke flywheel is more as compared to solid disk flywheel

Results obtained from mass minimization of solid disk flywheel gives $0.260 \mathrm{~m}$ optimal radius with thickness of $0.325 \mathrm{~m}$. Shape optimization by ANSYS shows optimal mass of solid disk flywheel is $52 \mathrm{~kg}$ for the $12 \%$ target reduction.

Outer diameter of $\operatorname{rim}\left(\mathrm{D}_{\mathrm{o} \mathrm{rim}}\right)=520 \mathrm{~mm}$ 
Table -2: Functional Values of Solid And Optimized six Spoke Flywheel

\begin{tabular}{|c|c|c|}
\hline Functional values & Solid Flywheel & $\begin{array}{c}\text { Optimized Six } \\
\text { Spoke } \\
\text { Flywheel }\end{array}$ \\
\hline Mass(Kg) & 60 & 52 \\
\hline $\begin{array}{c}\text { Moment of inertia(I) } \\
\text { Kg-m }\end{array}$ & 1.7594 & 2.4016 \\
\hline N (R.P.M.) & 738 & 738 \\
\hline $\begin{array}{c}\text { Kinetic energy( } \Delta \mathrm{E}) \\
\text { stored KJ }\end{array}$ & 5.253 & 7.171 \\
\hline Spe. Energy KJ/kg & 0.087 & 0.1379 \\
\hline Spe. Density KJ/m $\mathrm{m}^{3}$ & 653.37 & 1035.62 \\
\hline
\end{tabular}

\section{CONCLUSIONS}

- Flywheel geometry play very major role in performance of flywheel in thresher machine.

- With the help of experimental result we are able to success $12 \%$ material cost saving with less operational loads on to the shaft and bearing and high storing capacity of kinetic energy.

- Experimentally it is found that energy stored into the six spoke flywheel is more as compared to solid flywheel.

\section{REFERENCES}

[1]S. M. Dhengle "Investigation of stresses in arm type rotating flywheel"IJEST/vol.4/pp641-650.

[2] Mahesh C.Swami "Mass optimization of solid disk flywheel used in thresher machine" IOSR/Vol 12/Issue4/version-VII/p-ISSN:2320-334X

[3] S.M.Choudhary "Design optimization of flywheel of thresher using FEM" IJETA/ Vol. 3/ Issue 2,February 2013

[4] Sagar M.Samshette "Investigation of smart profile of flywheel”IJIET/Volume 5/Issue 4 August 2015/ISSN:23191058

\section{BIOGRAPHIES}

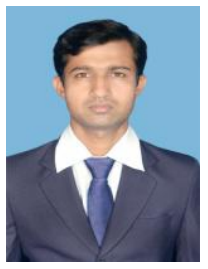

Mr. Sagar M. Samshette, M.E. Machine Design Student, Mechanical Department, M. S. Bidve Engineering College, Latur, Maharashtra, India

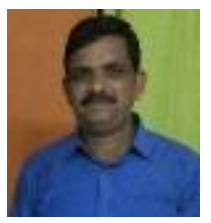

Prof. Mahesh C.Swami, Assistant Professor, Mechanical Department, M. S. Bidve Engineering College, Latur, Maharashtra, India 